\title{
Narrativas de professores de Física sobre a implementação de aulas experimentais: permanências e transformações
}

\section{Narratives of physics' teachers about the implementation of experimental classes: maintenances and changes}

\author{
Rodrigo Alexander Medeiros (rodrigoe.medeiros@gmail.com) \\ UFES - Universidade Federal do Espírito Santo \\ Leandro da Silva Barcellos (leandrobarcellos5@gmail.com) \\ PPGE/UFES - Universidade Federal do Espírito Santo
}

\begin{abstract}
Resumo: Esta pesquisa tem como objetivo investigar as trajetórias de professores de Física na implementação de aulas experimentais. Buscamos compreender as seguintes questões: que estratégias são utilizadas em aulas experimentais? Ao longo da carreira, essas estratégias foram consolidadas ou reformuladas? Quais elementos influenciaram esses processos? E de que forma? Para tanto, realizamos uma pesquisa qualitativa de caráter narrativo com quatro professores de Física do ensino básico, no primeiro semestre de 2018. Realizamos entrevistas narrativas, as quais foram coletadas por registros de áudio. A análise pautou-se na Análise Textual Discursiva. As narrativas evidenciam a ausência da experimentação no início de carreira dos professores, e a utilização do experimento em uma perspectiva verificacionista. Com o passar do tempo, alguns docentes mantiveram essa postura, enquanto outros repensaram suas ações. Os principais fatores que influenciaram esses processos foram a modalidade de ensino, a personalidade e o embasamento na literatura.
\end{abstract}

Palavras-chave: Experimentação no ensino de Física; Narrativas docentes; Desenvolvimento profissional.

Abstract: This research aims to investigate the trajectories of physics' teachers in the implementation of experimental classes. We try to understand: what strategies are used in experimental classes? Along the career, have these strategies been consolidated or reformulated? What elements influenced these processes? And in what way? For this, a qualitative narrative research has been conducted with four physics' teachers of basic education, in the first semester of 2018. As means of data collection narrative interviews were conducted and collected by audio records. The Discursive Textual Analysis was used as means of data analyses. The narratives indicate the absence of experimental classes in the first years of teachers' career, and the use of the experimentation in a verificationist perspective. Over time, some teachers maintained this attitude, whereas others change their approach. The main factors that influenced this process were the modality of education, the personality and the fundament in the scientific literature.

Palavras-chave traduzidas: Experimentation in physics teaching; Teacher narratives; Professional development.

\section{INTRODUÇÃO}

Parece haver certo consenso entre alunos, professores e elaboradores de currículos de que os cursos de Ciências precisam ter atividades experimentais (HODSON, 1988; 
GALIAZZI et al., 2001; ARAÚJO; ABIB, 2003; PENA; RIBEIRO FILHO, 2009; WESENDONK; TERRAZZAN, 2016; entre outros). Professores da educação básica concordam com a ideia de que a inclusão de aulas envolvendo experimentos, nos currículos, promoveria uma melhora no ensino de Ciências (BORGES, 2002). Isso nos ajuda a entender o elevado status que a experimentação possui, sendo entendida, algumas vezes, como resposta para todo e qualquer problema que se tenha no ensino de Ciências, mesmo que a literatura sinalize para o contrário (GALIAZZI et al., 2001).

Isto posto, trazemos o foco para a discussão sobre a inclusão e implementação de aulas experimentais no trabalho dos professores de Física. Antes, porém, é necessário distinguir de que experimentação estamos falando. A atividade experimental é caracterizada pela intrínseca relação que possui com o processo de produção de conhecimento das Ciências Naturais. Nesse sentido ela não é compreendida como sinônimo de atividade prática (que pode ser qualquer atividade feita na prática, como jogos, aulas de campo, construção de maquete, entre outros) ou atividade de laboratório (que pode ser, por exemplo, lavar a vidraria, que não possui compromisso direto com a produção de conhecimento científico) (MARANDINO, SELLES; FERREIRA, 2009).

Os experimentos no ensino de Ciências possuem uma série de funções pedagógicas, sendo utilizados pelos professores, em seus planejamentos, para ensinar Ciências, ensinar sobre a Ciência e ensinar como fazer Ciência (HODSON, 1988). Algumas das finalidades para o uso da experimentação no ensino são: ensinar o método científico, ensinar habilidades práticas, rejeitar evidência observacional; e demonstrar fenômenos e/ou comprovar leis previamente estudados (HODSON, 1988; BORGES, 2002).

Por mais apreciada e digna que seja a atividade experimental, ela nunca ganhará sentido somente pela própria existência. $\mathrm{O}$ fundamento em seu uso está condicionado à forma como o professor a conduz, tendo em vista as possibilidades que cada aparato oferece (LUCA et al., 2018).

Cabe ao professor decidir o momento e a forma como as atividades experimentais surgirão em suas aulas. Logo, é importante investigar os fatores que influenciam tal escolha. A partir deste cenário, esta pesquisa tem como objetivo investigar as trajetórias de professores de Física no desenvolvimento de aulas experimentais. Buscamos elementos que nos permitam compreender as seguintes questões: quais são as estratégias utilizadas pelos docentes ao conduzir aulas experimentais? Ao longo de suas 
carreiras, essas estratégias foram consolidadas ou reformuladas? Quais elementos influenciaram esses processos? E de que forma?

\section{ALGUNS ESTUDOS COM ENFOQUE NA EXPERIMENTAÇÃO NO ENSINO DE FÍSICA}

Wesendonk e Terrazzan (2016) realizaram uma revisão de literatura em um conjunto de dez periódicos acadêmico-científicos nacionais, com classificação da Coordenação de Aperfeiçoamento de Pessoal de Nível Superior (CAPES) variando entre A1 e B1 no âmbito da área de avaliação 'Ensino'. Foram selecionados artigos publicados entre 2009 e 2013, centrados na experimentação no ensino de Física.

Foi encontrada a frequência relativa de $9 \%$ em um total de 417 trabalhos. Além de considerar esse valor baixo, Wesendonk e Terrazzan (2016) alertam que na maior parte das produções não há um debate aprofundado de aportes teóricos referentes à utilização da experimentação no ensino. Para os mesmos autores isso implica em pouca contribuição desses trabalhos em relação a aspectos como, por exemplo, a utilização efetiva da experimentação no ensino de Física.

Buscando compreender essa questão da baixa frequência com que a atividade experimental aparece na literatura, direcionamos nosso olhar para o espaço escolar. Apesar de gozar de grande prestígio, as atividades experimentais acontecem pouco nas salas de aula (GALIAZZI et al., 2001). A frequência com que as atividades experimentais são realizadas, bem como a forma como são conduzidas, estão atreladas ao planejamento do professor. Quanto a isso, Carvalho e Gil-Pérez (2011) afirmam que uma das demandas formativas para professores de Ciências é saber preparar atividades capazes de gerar uma aprendizagem efetiva. Nas palavras desses autores:

\footnotetext{
O interesse por saber organizar atividades de aprendizagem manifesta-se como uma das necessidades formativas básicas dos professores. Inclusive aqueles que orientam o seu ensino como uma transmissão de conhecimentos já elaborados, consideram muito conveniente poder completar suas explicações com algum tipo de atividade dos alunos (CARVALHO; GILPEREZ, 2011, p. 43).
}

Os mesmos pesquisadores apontam que saber dirigir o trabalho dos alunos também surge como uma demanda formativa, principalmente quando se espera que os professores não sejam apenas transmissores de conteúdos. Contudo, quando as aulas prático-experimentais são realizadas na escola, normalmente, são desenvolvidas na 
forma de laboratório tradicional. Esta se caracteriza pela realização de atividades práticas envolvendo observação e medidas por parte dos estudantes, quase sempre com resultados previamente determinados pelo professor, o que aponta para um modelo verificacionista de Ciência (BORGES, 2002).

Araújo e Abib (2003) analisaram 106 trabalhos publicados entre 1992 e 2001 na Revista Brasileira de Ensino de Física, em seu encarte 'Física na Escola' e no 'Caderno Catarinense de Ensino de Física', almejando uma compreensão sobre as diferentes possibilidades e tendências dessas atividades. O trabalho resultou em um importante mapeamento sobre as formas de utilização da experimentação no ensino de Física em nível médio, no qual se destacam a predominância da área de Mecânica $(30,4 \%)$, da perspectiva qualitativa (66\%) e atrelamento a situações cotidianas (40\%), bem como os direcionamentos voltados a investigação, demonstração e verificação.

Araújo e Abib (2003) afirmam que existem diversas possibilidades para o uso das atividades experimentais no ensino médio. Porém, ressaltam que o sucesso da implementação das propostas está condicionado a forma como elas são planejadas, levando-se em consideração o contexto e as finalidades do trabalho experimental, a partir das diferentes perspectivas existentes para a condução das aulas dessa natureza.

Partimos do princípio de que investigar os momentos e contextos nos quais os entendimentos dos professores sobre experimentação se relacionam com o planejamento, e culminam na implementação em sala de aula, pode propiciar um aprofundamento das discussões sobre o uso da experimentação no ensino. Isso permitiria fundamentar melhor ações que auxiliem na efetivação dessas propostas no ambiente escolar.

\section{METODOLOGIA}

Neste artigo foi feita uma pesquisa de cunho qualitativo e de natureza narrativa. A pesquisa narrativa vem sendo utilizada no campo da pesquisa educacional e pode constituir-se como um poderoso método de investigação. Ela apresenta potencialidades como, por exemplo, processos de reflexão pedagógica e de formação, tanto na sua forma oral quanto escrita (GALVÃO, 2005).

As narrativas estabelecem uma interlocução entre as memórias de um indivíduo e sua trajetória, possibilitando uma autorreflexão sobre a própria vida, incluindo o percurso formativo. Podemos afirmar que existe uma relação dialética entre a narrativa 
e a experiência, uma vez que "assim como a experiência produz o discurso, este também produz a experiência” (CUNHA, 1997, p. 3).

A partir desta escolha metodológica, optamos pela entrevista narrativa não estruturada para a obtenção de dados. Concordamos com Jovchelovitch e Bauer (2002, p. 95-96) quando dizem que "a perspectiva do entrevistado se revela melhor nas histórias onde o informante está usando a sua própria linguagem espontânea na narração dos acontecimentos". Nossos sujeitos de pesquisa são quatro professores de Física da educação básica, com diferentes tempos de magistério, os quais chamaremos, de agora em diante, pelos seguintes nomes fictícios: Márcio, Fernando, Victor e João. Interessava-nos que eles narrassem à história de suas aulas envolvendo atividades experimentais. Assim sendo, propusemos a seguinte questão geradora para iniciar a entrevista:

Quero que você me conte a história das suas aulas experimentais no ensino de física. A melhor maneira de fazer isso seria você começar pelos seus primeiros anos na docência, contando como você conduziu suas aulas experimentais e então, passar a contar como elas foram desenvolvidas, uma após a outra, até os dias de hoje, podendo falar sobre suas estratégias, metodologias e/ou abordagens utilizadas. Você pode levar o tempo que for preciso para isso, podendo também dar detalhes, pois tudo o que for importante para você me interessa.

As entrevistas que realizamos foram individuais. Os áudios foram gravados e, posteriormente, transcritos. Elas ocorreram no primeiro semestre de 2018, e todos os sujeitos entrevistados consentiram suas participações e autorizaram as gravações, bem como a utilização dos dados produzidos para pesquisa.

Para analisar as entrevistas narrativas pautamo-nos nos pressupostos da Análise Textual Discursiva (ATD) (MORAES, 2003). A ATD é um movimento de interpretação dos significados do texto, realizado em três focos. O primeiro deles consiste em desmontar os textos (corpus), em um processo chamado de unitarização. Nesse processo os dados são analisados por meio da fragmentação do texto, com o intuito de criar as unidades de análise.

Em seguida, realiza-se a construção de categorias, buscando estabelecer relações entre as unidades de significado. São essas categorias que possibilitam a análise e compreensão dos discursos, e viabilizam o terceiro foco, que consiste na construção de um metatexto. "Os metatextos são constituídos de descrição e interpretação, 
representando o conjunto [...] de compreensão e teorização dos fenômenos investigados" (MORAES, 2003, p. 202).

O processo de análise fez emergir duas categorias, a saber: (i) a experimentação e o início da carreira docente e (ii) estratégias para a condução de aulas experimentais: permanências e transformações. Cada uma delas será discutida na seção seguinte, enquanto o metatexto será apresentado nas considerações finais.

\section{RESULTADOS E DISCUSSÕES}

Apresentamos a seguir as análises e as compreensões que emergiram a partir das narrativas dos professores. Para tanto, fragmentamos esta seção de acordo com as categorias de análise que estabelecemos. Procuramos delimitar os fenômenos que se expõe através da compreensão textual em níveis de sentidos conexos. É importante destacar que as categorias não são estanques, ou seja, as interpretações das narrativas podem extrapolar suas categorias (MORAES, 2003).

\section{1 - A experimentação e o início da carreira docente}

Nesta categoria alocamos os trechos das narrativas nos quais os professores relembraram o início de suas trajetórias. É importante realizar esse resgate, uma vez que boa parte dos conhecimentos do professor sobre o saber e o saber fazer de sua profissão provém de sua própria história, sobretudo de sua vida escolar, desde o ensino básico até o superior. Durante esse trajeto o professor acumula conhecimentos, crenças, representações e certezas sobre a prática docente (TARDIF, 2000). A narrativa do professor Fernando sinaliza para essa dimensão.

\footnotetext{
Fernando: Eu nunca tive experimentação na sala de aula quando aluno. Só fui ter experimentação quando estava aqui na Universidade Federal, no bacharelado. Então, as aulas que eu tenho de experimentação, que me fez muita diferença, foi (Física) Experimental III, com professor Fulano. A proposta dele era: ele passava a parte teórica, fazia experimentação e a gente tinha que anotar os dados para o relatório, e as avaliações, as provas mesmo e tal, era [sic] em cima do experimento. Eu não tenho essa oportunidade de fazer, por exemplo, uma ideia de uma prova em cima do experimento.
}

Fernando começou sua narrativa resgatando parte de sua trajetória discente. Ele revelou que não vivenciou aulas experimentais durante o ensino básico, e que seu primeiro contato com aulas dessa natureza foi na graduação. Fernando destacou a 
experiência vivida na disciplina de Física Experimental III, a qual ele disse que fez diferença em sua formação. Essa narrativa ratifica que as experiências vividas, mesmo enquanto aluno, podem influenciar a construção da imagem docente do saber-fazer. No final de sua fala, Fernando sugeriu ter aprovado a estratégia utilizada por seu professor, mas que não poderia adotá-la. Adiante ele revelou detalhes sobre as limitações que lhe foram impostas.

\begin{abstract}
Fernando: Trabalho como professor já tem nove anos, porém, no ensino básico, meu contato com as aulas envolvendo experimentação é recente. Enfim, mesmo com esse tempo todo eu não tive muito contato com experimentação por causa da categoria de ensino. Sempre trabalhei com preparatórios, e não tenho isso de maneira presente nas aulas.
\end{abstract}

Fernando revelou que seu contato com aulas experimentais foi recente, mesmo tendo quase uma década de magistério. Segundo ele, isso se deve ao fato de ter trabalhado, por muito tempo, em cursos preparatórios. Essa modalidade, normalmente, é caracterizada por aulas expositivas, utilizadas para dar conta da grande quantidade de conteúdos previstos para os certames. É também enfatizada a resolução de exercícios e, comumente, não se dedica tempo ao desenvolvimento de outras habilidades, uma vez que as provas do tipo exame costumam contemplar apenas a dimensão conceitual. Para Tardif (2000) a profissão docente exige que o professor se adapte à escola, a direção, entre outros. Assim, saber lidar com o contexto profissional torna-se tão importante quanto o conhecimento da matéria ensinada e o conhecimento pedagógico.

O professor Márcio iniciou sua narrativa resgatando os primeiros anos de sua carreira.

Márcio: Bom, logo quando eu comecei a lecionar eu fiquei um pouco assustado com a quantidade de conteúdos que tinha que ser dado num determinado tempo e, por conta dessa própria falta de tempo, no primeiro ano, eu decidi até não usar experimentos.

O docente revelou que não aderiu, a princípio, a aulas experimentais, optando por enfatizar os conteúdos conceituais. Essa decisão pode estar relacionada a uma supervalorização dessa dimensão. Entretanto, o ensino de ciências não deve se resumir ao ensino de conceitos. Lima e Maués (2006) chamam atenção para o conteúdo procedimental, que está relacionado ao saber fazer, e o conteúdo atitudinal, que diz respeito ao saber ser com os sujeitos. Para Azevedo (2004, p. 21) "a aprendizagem de procedimentos e atitudes se torna, dentro do processo de aprendizagem, tão importante quanto a aprendizagem de conceitos e/ou conteúdos". 
Márcio atribuiu à necessidade dessa decisão ao pouco tempo disponível para contemplar a grande quantidade de conteúdos a serem ensinados. Essa dimensão também pode ser vista no levantamento de Pena e Ribeiro Filho (2009), no qual a falta de tempo é apontada pelos professores como uma das dificuldades em se realizar atividades experimentais. O volume de conteúdos a serem ensinados, bem como a quantidade de aulas por semana, são elementos que precisam ser considerados pelo professor ao fazer o planejamento. É necessário tomar decisões sobre quais conteúdos serão enfatizados, e quais, eventualmente, sequer serão trabalhados. Essa decisão não é trivial, especialmente no contexto do início da carreira docente.

O professor João começou sua narrativa expondo alguns de seus entendimentos iniciais sobre experimentação.

João: Eu lembro que, nos primeiros anos que eu tava [sic] dando aula, eu tinha essa a mentalidade de que a atividade experimental poderia ser o grande atrativo para os alunos se interessarem. Aí eu fazia atividades de simples demonstração levando o experimento. Mostrava pro [sic] aluno: olha é assim que funciona, e às vezes o resultado não era o que eu esperava que fosse. Os alunos não se interessavam, não mostravam assim... Uma surpresa. [...] Então a maioria dos alunos não tinham [sic] essa vontade de entender como funciona $[$ sic $]$ os experimentos.

Segundo Tardif (2000) é comum que professores passem pelo curso de formação inicial sem modificar suas crenças anteriores sobre o ensino. E quando iniciam suas carreiras essas crenças tornam-se os principais norteadores das ações realizadas. É para essa direção que o início da narrativa de João aponta. Ele revelou um entendimento de que a experimentação poderia ser utilizada para despertar o interesse dos estudantes para os conteúdos escolares, o que sugere uma visão simplista do papel da experimentação.

Galiazzi et al. (2001) resgataram pesquisas feitas nos anos 60 e 90, nas quais motivar e manter o interesse na matéria foram apontados como justificativas para a realização de atividades experimentais nas escolas. Gonçalves, Biagini e Guaita (2017), na interlocução com diversos autores, destacam que pesquisas nacionais e internacionais têm revelado, direta e indiretamente, entendimentos preocupantes sobre experimentação entre participantes de cursos de licenciatura em Ciências da Natureza. Entre eles, compreensões que relacionam incondicionalmente os experimentos à motivação e à aprendizagem discente. Nesse sentido, é importante destacar que nem sempre as 
atividades experimentais são motivadoras para os alunos, como ocorrido no caso do professor João.

A narrativa do professor Victor expôs um elemento até então inédito nas entrevistas, relacionado a uma dimensão pessoal.

\begin{abstract}
Victor: Eu comecei a dar aula e ainda era aluno aqui da graduação do curso de Física. E, assim, eu nunca tive muita prática com aulas experimentais, com experimentos em si. Isso se deve muito ao meu jeito, assim... Primeiro que eu nunca tive aquela vocação de "Professor Pardal", de mexer, de furar, de cortar, parafusar [...] E um outro fato que também contribuiu pra [sic] pouca produção de aulas nesse sentido é, talvez, o fato da minha inclinação ser algo mais teórico. Eu acho que, se eu tivesse seguido uma linha de pesquisa, não seria nunca um físico experimental, seria um físico teórico.
\end{abstract}

O professor Victor revelou que começou a reger aulas ainda enquanto aluno de graduação, e atribuiu elementos de caráter pessoal a não realização de aulas experimentais. Segundo ele, o fato de não ter muitas habilidades manuais para lidar com materiais, e a falta de um "espírito inventivo" (como sugerido pela analogia com o 'Professor Pardal'), influenciaram em sua decisão de não trabalhar com experimentos. Nas profissões que envolvem interação humana, a personalidade do trabalhador se uni a prática, e constitui uma das principais formas de mediação da interação. Em seu trabalho o professor utiliza saberes de sua cultura pessoal, que está atrelada a sua história de vida, de modo que é muito difícil dissociar as pessoas de suas experiências. Isso nos ajuda a entender por que os professores, quando questionados sobre suas práticas, resgatam, por exemplo, aspectos de sua personalidade, habilidades pessoais e talentos, como elementos que contextualizam suas ações (TARDIF, 2000).

A narrativa de Victor sugere um entendimento de atividade experimental como sinônimo de atividade prática. Muitas aulas experimentais envolvem objetos, aparatos e equipamentos a serem manipulados pelo professor ou pelos estudantes. Esses recursos podem ser adquiridos, mas o alto custo costuma ser um problema. Em alguns casos, eles podem ser elaborados ou construídos, o que, de fato, exigiria algumas das habilidades mencionadas por Victor. Todavia, existem outras perspectivas para a implementação da experimentação no ensino de Física. É possível explorar experimentos de pensamento e o laboratório virtual, por meio do uso de applets e simulações. Essas modalidades não necessitam de habilidades manuais, porém, compreendemos que os "experimentos práticos" podem ser considerados mais atrativos, devido ao fator "mão na massa". 
Após resgatar elementos relativos ao início de carreira, os professores narraram detalhes sobre como eram as aulas envolvendo atividades experimentais. Eles expuseram estratégias utilizadas na elaboração e condução, bem como os elementos que influenciaram algumas de suas escolhas, e é isso que exploramos na categoria a seguir.

\title{
4.2 - Estratégias para a condução de aulas experimentais: permanências e
} transformações

Esta categoria abrange os trechos das narrativas em que os professores revelaram detalhes sobre a condução das aulas experimentais, bem como o contexto e os elementos que influenciaram tais escolhas. Buscamos, em uma perspectiva cronológica, identificar as estratégias utilizadas pelos docentes, visando compreender as perspectivas com as quais elas se aproximavam. Paralelamente, investigamos os fatores associados às transformações ou consolidações das estratégias.

O professor Fernando resgatou o momento da carreira no qual começou a trabalhar com aulas experimentais.

\begin{abstract}
Fernando: Já quando eu entrei na parte que eu podia aplicar experimentação, era uma coisa muito rápida e era também muito limitada. [...] Eu tive que fazer de maneira realmente livre. Livre que eu falo é que eu não tinha uma teoria que me desse à sustentação. Não porque eu não queria utilizar essa teoria, mas porque era muito controlado e eu não podia realmente usar devido a questões de escola mesmo, né, direção e tudo. [...] Eu chegava com equipamento na sala, na maioria das vezes com somente um experimento para apresentar pra [sic] turma inteira. Fazia uma abordagem simples do experimento, entrava com a teoria e mostrava alguns resultados que a teoria previa.
\end{abstract}

Fernando caracterizou suas primeiras aulas experimentais como sendo rápidas e limitadas. Ele utilizou o termo 'livre' para se referir à ausência de uma base teóricometodológica que sustentasse as ações, reforçando que isso se deu em virtude da instituição na qual atuava. A abordagem descrita por esse professor aproxima-se da perspectiva verificacionista, visto que o experimento era utilizado para ilustrar resultados previamente estudados. Os professores Victor e João narraram experiências semelhantes.

Victor: E aí, ao longo de muitos anos, as experiências que tive em sala de aula com experimentos eram experimentos pequenos, experimentos extremamente simples, né, que pudessem demonstrar, por exemplo, uma coisa que tá $[\mathrm{sic}]$ sendo dita ali naquele momento [...]. 
João: E eu tava [sic] ali pra [sic] demonstrar, pra [sic] pegar eu mesmo o experimento e mostrar pra eles (os alunos) [...].

Para Hodson (1988, p. 9) “a função pedagógica de muitos 'experimentos' no ensino da ciência é ilustrar um ponto de vista teórico em particular". Essa perspectiva, ainda recorrente no ensino de Física, atribui um papel passivo aos estudantes, em que eles apenas recebem os conhecimentos científicos acumulados. Essa abordagem didática é questionável, dado que ela sugere uma visão do conhecimento científico como algo imutável, inegociável e não problemático. Ela centraliza as ações no professor, que as protagoniza juntamente com os discursos da aula, atribuindo-lhe um papel de fonte de conhecimento (HODSON, 1988).

Vale destacar que o modelo verificacionista pode prejudicar o próprio professor. Ao se deparar com um experimento que "não deu certo", o docente tende a aboli-lo de seu repertório, desperdiçando a oportunidade de investigar o que houve para construir novos conhecimentos (HODSON, 1988). Fernando complementou sua narrativa descrevendo outra de suas ações:

Fernando: Eu tenho experiência dando aula de robótica pro [sic] ensino fundamental II. [...] Infelizmente, as escolas particulares, elas insistem com que você faça abordagem em cima daquele material. [...] Então como que eu faço, por exemplo, nas aulas de robótica e até mesmo nas aulas de Física que têm experimentação, eu sigo o roteiro do material didático.

A narrativa de Fernando expôs a realização de aulas baseadas em um roteiro. Essa perspectiva aproxima-se do que Borges (2002) denomina de laboratório tradicional, caracterizado pela realização de atividades práticas, por parte dos estudantes, a partir de orientações pré-definidas pelo professor ou roteiros estruturados. A mesma dimensão pode ser vista na trajetória do professor Victor.

Victor: [...] o último (experimento) deu bastante trabalho, mas foi legal. Eles (os alunos) foram utilizar o circuito com roteiro [...]. Com o roteiro eles tinham que ir manipulando o circuito elétrico e fazendo observações do que aconteceu $[\ldots]$.

Ainda segundo Borges (2002), uma das principais críticas feitas às atividades baseadas em roteiros é que, em geral, os estudantes não dão relevância a elas, uma vez que as questões e os procedimentos já são pré-determinados. Além disso, a montagem do equipamento e a busca por respostas esperadas costumam consumir a maior parte do tempo da atividade. 
O professor Márcio também narrou detalhes de suas primeiras aulas

experimentais.

Márcio: [...] assim como sempre a gente lê, tendo informação que o experimento pode auxiliar na assimilação do conteúdo, eu resolvi tentar aplicar uma aula experimental [...] mas eu não queria prejudicar, em hipótese alguma, o conteúdo ministrado nas aulas expositivas. Então o que eu fiz foi acumular tempo extra, de forma que sobrasse um tempo afim de eu aplicar aulas com experimentos e, obviamente, isso foi após o conteúdo da matéria. $\mathrm{E}$ eu percebi que, na realidade, não houve interesse nenhum dos alunos com relação a isso, porque eles estavam acostumados a verificar aquele conteúdo do aprendizado no papel [...] então decidi que aquilo não foi uma boa estratégia.

A narrativa de Márcio revelou que ele ainda priorizava os conteúdos das aulas expositivas conceituais, mas que, a partir de leituras, decidiu investir em aulas experimentais. A primeira estratégia consistiu em adiantar os conteúdos conceituais para que, ao final, sobrasse tempo para a utilização de experimentos. $\mathrm{O}$ docente contou que os estudantes não apresentaram nenhum interesse pelos experimentos, e diagnosticou que isso era devido ao condicionamento ao qual ele havia submetido os alunos. Segundo Márcio, os discentes estavam tão acostumados com os fenômenos no plano teórico que não conseguiam enxergá-los no contexto real. E, por consequência, não se interessavam pela aula experimental. Márcio encerrou sua narrativa afirmando que, com base na reação dos alunos, concluiu que a estratégia adotada não foi boa. Em seguida ele relatou como lidou com isso.

Márcio: Então o que eu resolvi fazer, resolvi aplicar antes do conteúdo, como uma forma de atrair os alunos para adquirir aquele conhecimento e saber por que aquele fenômeno tá [sic] acontecendo. [...] com relação a isso, o interesse na aula experimental foi muito melhor. Realmente eles participaram da aula, né, eles perguntaram, né, porque aquilo estava acontecendo. Eu demonstrava vários experimentos de eletrostática, e, aparentemente, foi ótimo. Mas, na aula seguinte, já quando a gente já estava trabalhando aquele conteúdo, não havia mais interesse nenhum, e não havia também nenhum tipo de conexão do aluno com o fenômeno, do aprendizado do aluno naquele momento de aula expositiva com o fenômeno.

Márcio revelou que inverteu a ordem das ações, passando a realizar as aulas experimentais antes de trabalhar os conteúdos conceituais. Ele sinalizou para o uso do experimento como uma forma de atrair o interesse dos estudantes para os conteúdos a serem estudados, semelhante ao que foi exposto pelo professor João na subseção anterior. Além disso, Márcio afirmou que a condução da aula era baseada em demonstrações realizadas por ele, similar ao relatado por Victor e João. 
Segundo Márcio, a princípio, os resultados dessa mudança de estratégia foram positivos, e os estudantes tiveram uma participação mais efetiva na aula. Porém, o professor afirmou que, quando retomava as aulas expositivas, o interesse dos estudantes desaparecia, e eles não realizavam conexões entre o que foi visto na demonstração e o que estava sendo exposto na aula teórica. Nota-se que a visão simplista do experimento como um motivador se fez mais uma vez presente e, assim como no caso do professor João, os resultados foram distintos em relação ao desejado pelos docentes. Seguidamente, Márcio deu continuidade a narrativa:

Márcio: Aí eu fiquei doido (risos). Poxa, antes, fazer o experimento depois do conteúdo não foi tão bom. Fazer antes foi parcialmente bom, mas também não foi ótimo, né, e buscando melhorar isso eu tentei então levar experimentos menores [...] pra [sic] poder participar de uma aula expositiva [...]. Essa aí foi ótimo [sic]. Assim, não teve tanto interesse por parte dos alunos quanto nas aulas dedicadas inteiramente a experimentos [...]. Aí nesse tipo de aula expositiva, com o experimento, já não tem essa participação bem efetiva. Em compensação, eu consegui ver que eles assimilaram muito melhor o conteúdo, porque quando você tá passando o conteúdo e demonstra no experimento, mesmo que seja rápido, eles parecem que entendem o fenômeno físico mesmo [...] eles fazem, inclusive, perguntas mais fundamentais mesmo sobre o experimento [...]. Eu acho que esse é um dos melhores métodos. Pelo menos comigo foi, né, de aplicação de experimentos.

Márcio demonstrou certa frustração com os insucessos obtidos nas duas estratégias anteriores. Buscando uma melhora nos resultados, ele decidiu utilizar experimentos de curto tempo de realização, de modo que a discussão teórica pudesse ser desenvolvida em paralelo. Ele julgou o resultado como sendo ótimo, exaltando que houve uma melhor assimilação por parte dos estudantes, e finalizou afirmando que, com base em suas experiências, esse foi um dos melhores métodos para a utilização de experimentos em aulas de Física.

A trajetória de Márcio apresentou o uso de diferentes estratégias para a condução de aulas experimentais. Apesar de sinalizar para uma consulta a literatura, nota-se que muitas de suas ações foram guiadas por "tentativa e erro", em que ele foi aplicando estratégias e analisando os resultados até obter um posicionamento final sobre qual seria o melhor método. Segundo Tardif (2000, p. 14) "ainda hoje, a maioria dos professores aprendem a trabalhar na prática, às apalpadelas, por tentativa e erro". Segundo o mesmo pesquisador, o início de carreira é um momento de exploração em que o professor, aos poucos, vai estabelecendo sua prática profissional.

Os primeiros anos de docência também são fundamentais na aquisição do sentimento de confiança e competência. Assim, o professor adapta e transforma suas 
estratégias em função das particularidades e rendimento da turma, visto que seus saberes estão a serviço da ação, e é na ação que as estratégias ganham significado e utilidade. Nesse sentido, a forma como o aluno reage às estratégias adotadas torna-se um termômetro para repensar as ações. A relação professor-aluno, construída diariamente ao longo do ano letivo, desenvolve no docente um conhecimento de si, de seus valores e emoções, e também do alcance destes na sua maneira de ensinar (TARDIF, 2000).

Após um início marcado por uma visão simplista da experimentação como um motivador para o aprendizado dos conteúdos, e aulas conduzidas na perspectiva verificacionista, as quais não renderam os resultados almejados, o professor João retomou sua trajetória com aulas experimentais.

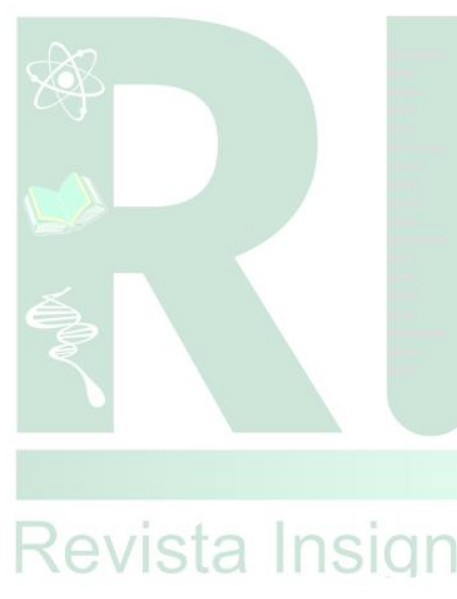

João: Depois eu comecei atuar na escola na rede pública, né, na rede estadual. Aí eu tive outras experiências, e ai não eram atividades isoladas meramente demonstrativas. [...] Eu planejava uma sequência de aulas sobre um assunto, e dentro dessa sequência de aulas tinha o experimento. Eu pedia pros [sic] alunos pesquisarem como seria a realização daquele experimento e assim a gente foi conduzindo uma atividade ou outra, [...] Era mais foco nas sequências de aulas e aprendizagem dos alunos, e, dentro disso, tinha uma parte experimental, tinha a parte de investigar, tinha parte de conversas, de filme etc. Então era [sic] diversos recursos utilizados pra [sic] poder alcançar o objetivo, e dentre eles, tava [sic] lá o experimento. [...] E nessa época também eu tive experiências com kits de materiais associados com atividades fora da escola, de educação não formal. A gente planejava, pegava um kit realizava algum estudo do experimento. Depois ia num espaço especifico que também tinha aquele mesmo experimento, que os alunos se aprofundavam, e olhavam e escutavam pelo olhar de outra pessoa, a maneira como interpretava aquele fenômeno [...].

João sinalizou para uma mudança da rede privada de ensino para a rede pública estadual. Ele não esclareceu se era submetido a imposições, por parte da instituição contratante, como o professor Fernando. João revelou que se afastou da perspectiva de aulas experimentais isoladas e demonstrativas, passando a trabalhar com experimentos no contexto de sequências de aulas. A literatura apresenta tais sequências tanto no contexto do planejamento dos professores quanto em pesquisas acadêmicas. Diferentes autores, a partir de bases teórico-metodológicas distintas, têm defendido a utilização de sequências de aulas no ensino de ciências, relatando resultados importantes relativos a influências delas no aprendizado dos estudantes (GIORDAN; GUIMARÃES; MASSI, 2012).

O professor João não esclareceu que perspectiva utilizava para construir suas sequências, nem como elas eram conduzidas. Porém, ele afirmou que seu foco era o 
aprendizado dos alunos. Para tanto, João utilizava recursos como experimento, filmes e conversas, além de colocar os estudantes para pesquisarem sobre a realização do experimento. Em seguida ele narrou outra perspectiva para o uso de atividades experimentais. O docente realizava um planejamento que envolvia o uso de um kit de experimentos. Posteriormente, era articulada uma visita a um espaço não formal de educação que tivesse um equipamento relacionado ao kit estudado. $\mathrm{O}$ professor não expôs detalhes sobre a condução dessas aulas, nem sobre como era à articulação entre escola e espaço não formal, mas exaltou que os estudantes olhavam e escutavam pelo viés de outra pessoa, possivelmente o mediador (ou monitor) do local.

Gouvêa et al. (2001) sinalizam que professores comumente utilizam espaços não formais como extensão da sala de aula, sugerindo entender essa relação como sendo suplementar. Nesse sentido, Marandino (2001) destaca que o importante nessa articulação é a maneira como o conhecimento será estabelecido em tal contexto. A mesma autora defende que se deve buscar a ampliação da cultura dos estudantes a partir de correlações com os conhecimentos que estão sendo trabalhados nas aulas. João concluiu apresentando uma reflexão sobre essa mudança de estratégia.

João: Acho que a grande sacada foi essa mudança do olhar do experimento como, primeiramente, o recurso a salvar o ensino de física, que é uma grande ilusão, que se você não tiver um planejamento, uma estruturação adequada, você vai se frustrar, como qualquer outra coisa que você for fazer [...] Então acho que foi com essas experiências que tive a grande percepção.

Pesquisadores: E essa mudança na abordagem da experimentação, ela se deve a que?

João: Então, tem dois focos que vão influenciar. Primeiro é o aprofundamento na própria literatura, né, conhecer alguns materiais, algumas pesquisas que tiveram essas diferentes percepções pra [sic] poder falar: olha, dependendo do que você tá fazendo, né, não que você tá fazendo errado, aí você não vai alcançar seus objetivos, vai se frustrar. Aí na literatura a área é vasta, fala bastante coisa sobre isso [...]. E a experiência, né, ver como os alunos reagem. Aí quando a gente bota esses dois ingredientes e faz uma mistura, você percebe que, realmente, o melhor caminho a seguir é ter um planejamento sólido [...].

As narrativas de João e Márcio apresentam algumas características semelhantes. Ambos iniciaram suas aulas experimentais guiados por uma visão simplistas do papel da experimentação e, a partir dos resultados obtidos em sala, refletiram e concluíram que aquelas estratégias não eram as mais efetivas. Segundo Tardif (2000) os saberes profissionais são saberes da ação, ou seja, eles são trabalhados e incorporados no 
processo da prática docente. É importante destacar que esses saberes não são os conhecimentos transmitidos nos cursos de formação inicial, eles são saberes da prática.

Além da reflexão sobre a prática, João destacou o aprofundamento na literatura de uma forma mais explícita que Márcio. Segundo João, conhecer pesquisas com diferentes percepções sobre o uso da experimentação no ensino o ajudou a pensar sobre os objetivos a serem almejados nas aulas, a partir da forma como elas são conduzidas. Nesse sentido, ele destacou que a base teórica, aliada à reflexão sobre a prática, o levou a concluir que um planejamento sólido é o melhor caminho para se trabalhar a experimentação no ensino de Física. Essa fusão merece destaque, pois a prática profissional não se resume a aplicação de conhecimentos acadêmicos. Pelo contrário, ela exige reflexão e discernimento, por parte dos docentes, para que possam realizar adaptações e transformações frente aos desafios que se apresentam (TARDIF, 2000).

\section{CONSIDERAÇÕES FINAIS}

O início de carreira dos nossos sujeitos foi marcado pela ausência de aulas experimentais. Fatores como a modalidade de ensino, ênfase na dimensão conceitual e aspectos da personalidade foram apontados como elementos que influenciaram nas decisões dos professores. As primeiras investidas no campo da experimentação vieram com o passar do tempo, e sinalizaram para um viés simplista do trabalho experimental, no qual ele serviria para motivar os alunos e visualizar os fenômenos. Para tanto, as principais estratégias adotadas foram a demonstração e atividades roteirizadas, as quais aproximam-se da perspectiva verificacionista.

Dois dos nossos sujeitos de pesquisa revelaram que, no decorrer de suas carreiras, suas estratégias para a condução de aulas experimentais se mantiveram: Fernando, em função das condições impostas pela instituição na qual atuava, o que corrobora a ideia de que os saberes docentes são situados; e Victor, em virtude de aspectos de sua personalidade, o que ratifica que os saberes docentes são, também, personalizados.

Outros dois professores revelaram que, com o passar do tempo, suas estratégias sofreram transformações, influenciadas, de certa forma, pela literatura e, principalmente, pelos resultados obtidos no trabalho de sala de aula. Na medida em que o desempenho dos alunos não era como o esperado, Márcio e João reformularam a maneira de conduzir as aulas. Muitas vezes, aproximando-se do método da tentativa e erro. Eles variaram o momento em que o experimento era utilizado e o contexto com o 
qual ele se articulava. Assim, estes professores chegaram a diferentes conclusões sobre qual é a melhor forma de conduzir aulas experimentais, o que sinaliza para a heterogeneidade dos saberes construídos e mobilizados pelos professores no exercício da prática.

A análise das trajetórias dos sujeitos, que é uma contribuição trazida por este estudo, auxilia na compreensão sobre como ocorre o processo de escolhas metodológicas dos docentes e a formação de seus repertórios. Isso nos fornece subsídios para o (re)pensar em ações no âmbito da formação inicial e continuada de professores com vistas ao desenvolvimento profissional, no que tange a escolha de abordagens e metodologias mais eficazes para o ensino de Ciências.

Como implicações, apontamos a importância da realização de estudos mais amplos sobre o saber e o saber-fazer que os docentes desenvolvem em seus cotidianos. Tais estudos podem investigar, de forma mais profunda, os elementos que influenciam as escolhas metodológicas dos professores, por exemplo, e como eles se desdobram com o passar do tempo.

\section{REFERÊNCIAS}

ARAÚJO, M. S. T.; ABIB, M. L. V. S. Atividades experimentais no Ensino de Física: diferentes enfoques, diferentes finalidades. Revista Brasileira de Ensino de Física, v. 25, n.2, p. 176-194, 2003.

AZEVEDO, M. C. P. S. Ensino por investigação: problematizando as atividades em sala de aula. Ensino de ciências: unindo a pesquisa e a prática. In: CARVALHO, A. M. P. (Org.). São Paulo: Pioneira Thomson Learning, p. 19-33, 2004.

BORGES, A. T. Novos rumos para o laboratório escolar de ciências. Caderno Brasileiro de Ensino de Física, v. 19, n. 3, p. 291-313, 2002.

CARVALHO, A. M. P.; GIL-PÉREZ, D. Formação de professores de ciências: tendências e inovações. 10.ed. São Paulo: Cortez, 128 p, 2011.

CUNHA, M. I. da. Conta-me agora! As narrativas como alternativas pedagógicas na pesquisa e no ensino. Revista da Faculdade de Educação, vol. 23, n. 1-2. São Paulo, Jan./Dec. 1997. 
GALIAZZI， M. C.; ROCHA， J. M. B.; SCHMITZ， L. C.; GIESTA， S. M.; GONÇALVES, F. P. Objetivos das atividades experimentais no ensino médio: a pesquisa coletiva como modo de formação de professores de Ciências. Ciência e Educação, Bauru, v. 7, n. 2, p. 249-263, 2001.

GALVÃO, C. Narrativas em educação. Ciência \& Educação, v. 11, n. 2, p. 327-345, 2005 .

GIORDAN, M.; GUIMARÃES, Y.; MASSI, L. Uma análise das abordagens investigativas de trabalhos sobre sequências didáticas: tendências no Ensino de Ciências. In: VIII Encontro Nacional de Pesquisa em Educação em Ciências e I Congresso Iberoamericano de Educação em Ciências, 2012, Campinas, SP. Atas do VIII ENPEC - I CIEC. Rio de Janeiro, RJ: ABRAPEC, v. 1. p. 1-12, 2012.

GONÇALVES, F. P.; BIAGINI, B.; GUAITA, R. I. As atividades experimentais na formação de professores de química: permanências e transformações. In: XI Encontro Nacional de Pesquisa em Educação em Ciências, 2017, Florianópolis. Anais... Florianópolis: ENPEC, p. 1-9, 2017.

GOUVÊA, G.; VALENTE, M. E.; CAZELLI, S.; MARANDINO, M. Redes Cotidianas de Conhecimento e os Museus de Ciência. Parcerias Estratégicas (Brasília), Brasília, n.11, p. 169-174, 2001.

HODSON, D. Experiments in Science and Science Teaching. Educational Philosophy and Theory. v. 20, n. 2, p. 53-66, 1988.

JOVCHELOVITCH, S.; BAUER, M. W. Entrevista narrativa. In Bauer, M. W., Gaskell, G. (Orgs.). Pesquisa qualitativa com texto, imagem e som. Um manual prático. Petrópolis, RJ: Vozes, p. 90-113, 2002.

LIMA, M. E. C. C.; MAUÉS, E. R. C. Uma releitura do papel da professora das séries iniciais no desenvolvimento e aprendizagem de ciências das crianças. Ensaio Pesquisa em Educação em Ciências, v. 8, n. 2, p. 161-175, 2006.

LUCA, A. G.; SANTOS, S. A.; DEL PINO, J. C.; PIZZATO, M. C. Experimentação contextualizada e interdisciplinar: uma proposta para o ensino de ciências. Revista Insignare Scientia - RIS, v. 1, n. 2, p. 1-21, 2018.

MARANDINO, M. Interfaces na relação museu-escola. Caderno Catarinense de Ensino de Física, v. 8, n. 1, p. 85-100, 2001. 
MARANDINO, M.; SELLES, S.; FERREIRA, M. Ensino de Biologia: histórias e práticas em diferentes espaços educativos. São Paulo: Cortez, p. 216, 2009.

MORAES, R. Uma tempestade de luz: a compreensão possibilitada pela análise textual discursiva. Ciênc. educ. v.9, n. 2, p. 191-211, 2003.

PENA, F. L. A.; RIBEIRO FILHO, A. Obstáculos para o uso da experimentação no ensino de Física: um estudo a partir de relatos de experiências pedagógicas brasileiras publicados em periódicos nacionais da área (1971-2006). Revista Brasileira de Pesquisa em Educação em Ciências, v. 9, n. 1, p. 4, 2009.

TARDIF, M. Saberes Profissionais dos Professores e Conhecimentos Universitários: elementos para uma epistemologia da prática profissional dos professores e suas consequências em relação à formação para o magistério. Revista Brasileira de Educação. ANPED, São Paulo, n. 13, p. 5-24, jan./abr, 2000.

WESENDONK, F. S.; TERRAZZAN, E. A. Caracterização dos focos de estudo da produção acadêmico-científica brasileira sobre experimentação no Ensino de Física. Caderno Brasileiro de Ensino de Física, v. 33, n. 3, p. 779-821, 2016. 